\title{
(6) \\ Pain in young people aged 13 to 17 years with cerebral palsy: cross-sectional, multicentre European study
} OPEN ACCESS

\author{
Kathryn N Parkinson, ${ }^{1}$ Heather 0 Dickinson, ${ }^{1}$ Catherine Arnaud, ${ }^{2}$ Alan Lyons, ${ }^{3}$ \\ Allan Colver, ${ }^{1}$ on behalf of the SPARCLE group
}

${ }^{1}$ Institute of Health and Society, Newcastle University, Newcastle upon Tyne, UK ${ }^{2}$ INSERM, UMR1027, Université Paul-Sabatier, CHU Purpan, Service d'Epidémiologie Clinique, Toulouse, France

${ }^{3}$ Enable Ireland, Lavanagh Centre, Ballintemple, Cork, Ireland

\section{Correspondence to} Professor Allan Colver, Institute of Health and Society, Newcastle University, Newcastle upon Tyne NE2 4AX, UK;

allan.colver@ncl.ac.uk

Received 3 December 2012 Revised 17 March 2013 Accepted 24 March 2013 Published Online First 20 April 2013

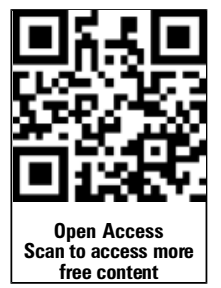

To cite: Parkinson KN Dickinson HO, Arnaud C, et al. Arch Dis Child 2013;98:434-440.

\section{ABSTRACT}

Objective To determine the prevalence and associations of self- and parent-reported pain in young people with cerebral palsy (CP).

Design and setting Cross-sectional questionnaire survey conducted at home visits in nine regions in seven European countries. Participants were 13 to 17 -year-olds $(n=667)$ drawn from population CP registers in eight regions and from multiple sources in one region. 429 could self-report; parent-reports were obtained for 657 . Data were collected on: severity, frequency, site and circumstances of pain in previous week; severity of pain associated with therapy in previous year.

Results The estimated population prevalence of any pain in previous week was $74 \%(95 \% \mathrm{Cl} 69 \%$ to $79 \%)$ for self-reported pain and $77 \%(95 \% \mathrm{Cl} 73 \%$ to $81 \%)$ for parent-reported pain. $40 \%$ experienced leg pains, $34 \%$ reported headaches and $45 \%$ of those who received physiotherapy experienced pain during therapy. Girls reported more pain than boys $(O R=2.1,95 \% \mathrm{Cl}$ 1.5 to 3.0) and young people reported more pain if they had emotional difficulties (comparing highest and lowest quartiles: $\mathrm{OR}=3.1,95 \% \mathrm{Cl} 1.7$ to 5.6). Parents reported more pain in children with emotional difficulties $(\mathrm{OR}=4.2,95 \% \mathrm{Cl} 2.7$ to 6.6$)$, or with more impaired walking ability.

Conclusions Pain in young people with CP is highly prevalent. Because pain causes immediate distress and is associated with lower subjective well-being and reduced participation, clinicians should routinely assess pain. Clinical interventions to reduce pain should be implemented and evaluated. The efficacy of medical and therapeutic interventions causing pain should be re-examined to establish if their benefit justifies the pain and fear of pain that accompany them.

\section{INTRODUCTION}

The literature on pain in adolescents with cerebral palsy (CP) is small but there have been two recent studies. The first ${ }^{1}$ reported pain in a populationbased sample across the severity spectrum from young people's self-reports where possible and otherwise from parents' reports; analyses combined these as if they were equivalent. The second ${ }^{2}$ reported pain from one sample derived from organisations that work with young people with $\mathrm{CP}$ and one from a hospital-based group; results may therefore be unrepresentative of young people with CP.

In a large European Study, SPARCLE (Study of PARticipation of children with Cerebral palsy Living in Europe), ${ }^{3}$ of 8 to 12 -year-old children with $C P$, pain was very prevalent ${ }^{4}$ and was consistently associated with lower subjective well-being ${ }^{5}$ and reduced participation. ${ }^{6}$ Therefore when the

\section{What is already known on this topic}

- Pain in young people with cerebral palsy is associated with lower subjective well-being and reduced participation.

- There are many potential causes of pain in cerebral palsy such as spasms, hip subluxation, contractures, operation sites, therapeutic interventions, assistive devices and gastrostomy tubes.

\section{What this study adds}

- Pain in young people with cerebral palsy is very prevalent: about $75 \%$ experience some pain in a typical week. Strategies to reduce pain appear to be absent or inadequate.

- Clinicians should routinely assess pain and develop pain management plans if necessary.

- Much pain is caused by clinical procedures or therapies; their efficacy should be re-examined to establish if they deliver sufficient benefit to justify the pain and fear of pain that accompany them.

young people were visited again aged 13 to 17 years (SPARCLE2), ${ }^{7}$ we collected more detailed information about pain.

In this paper we report self- and parent-reported pain, and analyse these separately. We report prevalence of pain, sites and circumstances of pain, and examine the associations of pain with young people's impairments and emotional difficulties, parenting stress and sociodemographic characteristics. We also compare self-reports of pain with parents' reports of their child's pain.

\section{METHODS}

The methods of the SPARCLE studies have been described in detail elsewhere ${ }^{3}$ 7-9 and are summarised briefly below.

\section{Participants}

SPARCLE1 randomly sampled 1174 children from population-based registers of children with CP. Children were eligible if born between 31 July 1991 and 1 April 1997. The registers cover eight regions of six European countries (table 1) that share a standardised definition and classification of $\mathrm{CP}^{10}$ One 
Table 1 Distribution of impairments, sociodemographic characteristics, pain, emotional difficulties score and total stress score

\begin{tabular}{|c|c|c|c|c|}
\hline & \multicolumn{2}{|c|}{$\begin{array}{l}\text { Self-reported } \\
(n=429)\end{array}$} & \multicolumn{2}{|c|}{$\begin{array}{l}\text { Parent-reported } \\
(n=657)\end{array}$} \\
\hline & $\mathrm{n}$ & $(\%)$ & $\mathbf{n}$ & $(\%)$ \\
\hline \multicolumn{5}{|l|}{ Impairments of young people } \\
\hline \multicolumn{5}{|l|}{ Walking ability as captured by gross motor function } \\
\hline I. Walks without limitation & 199 & $(46 \%)$ & 226 & $(34 \%)$ \\
\hline II. Walks with limitation & 84 & $(20 \%)$ & 113 & $(17 \%)$ \\
\hline III. Walks with assistive devices & 58 & $(14 \%)$ & 85 & $(13 \%)$ \\
\hline IV. Unable to walk, limited self-mobility & 50 & $(12 \%)$ & 90 & $(14 \%)$ \\
\hline V. Unable to walk, severely limited self-mobility & 37 & $(9 \%)$ & 143 & $(22 \%)$ \\
\hline Information not available & 1 & $(0 \%)$ & 0 & $(0 \%)$ \\
\hline \multicolumn{5}{|l|}{ Seizures } \\
\hline No seizures, not on medication & 367 & $(86 \%)$ & 464 & $(71 \%)$ \\
\hline No seizures, on medication & 23 & $(5 \%)$ & 73 & $(11 \%)$ \\
\hline Seizures less than once a month & 19 & $(4 \%)$ & 46 & $(7 \%)$ \\
\hline Seizures between once a month and once a week & 9 & $(2 \%)$ & 24 & $(4 \%)$ \\
\hline Seizures more than once a week & 6 & $(1 \%)$ & 45 & $(7 \%)$ \\
\hline Information not available & 5 & $(1 \%)$ & 5 & $(1 \%)$ \\
\hline \multicolumn{5}{|l|}{ Intellectual ability } \\
\hline $\mathrm{IQ}>70$ & 286 & $(67 \%)$ & 300 & $(46 \%)$ \\
\hline IQ 50-70 & 129 & $(30 \%)$ & 169 & $(26 \%)$ \\
\hline $\mathrm{IQ}<50$ & 13 & $(3 \%)$ & 187 & $(28 \%)$ \\
\hline Information not available & 1 & $(0 \%)$ & 1 & $(0 \%)$ \\
\hline \multicolumn{5}{|l|}{ Cerebral palsy subtype } \\
\hline Unilateral spastic & 175 & $(41 \%)$ & 208 & $(32 \%)$ \\
\hline Bilateral spastic & 208 & $(48 \%)$ & 354 & $(54 \%)$ \\
\hline Dyskinetic & 28 & $(7 \%)$ & 62 & $(9 \%)$ \\
\hline Ataxic & 13 & $(3 \%)$ & 28 & $(4 \%)$ \\
\hline Information not available & 5 & $(1 \%)$ & 5 & $(1 \%)$ \\
\hline \multicolumn{5}{|l|}{ Sociodemographic characteristics } \\
\hline \multicolumn{5}{|l|}{ Regions } \\
\hline Southeast France & 41 & $(10 \%)$ & 61 & $(9 \%)$ \\
\hline Southwest France & 38 & $(9 \%)$ & 57 & $(9 \%)$ \\
\hline Southwest Ireland & 52 & $(12 \%)$ & 76 & $(12 \%)$ \\
\hline West Sweden & 40 & $(9 \%)$ & 66 & $(10 \%)$ \\
\hline North England & 73 & $(17 \%)$ & 107 & $(16 \%)$ \\
\hline Northern Ireland & 64 & $(15 \%)$ & 88 & $(13 \%)$ \\
\hline East Denmark & 53 & $(12 \%)$ & 86 & $(13 \%)$ \\
\hline Central Italy & 17 & $(4 \%)$ & 42 & $(6 \%)$ \\
\hline Northwest Germany & 51 & $(12 \%)$ & 74 & $(11 \%)$ \\
\hline \multicolumn{5}{|l|}{ Gender } \\
\hline Boys & 249 & $(58 \%)$ & 376 & $(57 \%)$ \\
\hline Girls & 180 & $(42 \%)$ & 281 & $(43 \%)$ \\
\hline \multicolumn{5}{|l|}{ Age in years } \\
\hline$<13$ & 27 & $(6 \%)$ & 45 & $(7 \%)$ \\
\hline 13 & 99 & $(23 \%)$ & 137 & $(21 \%)$ \\
\hline 14 & 85 & $(20 \%)$ & 135 & $(21 \%)$ \\
\hline 15 & 91 & $(21 \%)$ & 131 & $(20 \%)$ \\
\hline 16 & 76 & $(18 \%)$ & 114 & $(17 \%)$ \\
\hline 17 & 47 & $(11 \%)$ & 83 & $(13 \%)$ \\
\hline$>17$ & 4 & $(1 \%)$ & 12 & $(2 \%)$ \\
\hline Information not available & 5 & $(1 \%)$ & 9 & $(1 \%)$ \\
\hline \multicolumn{5}{|l|}{ Pain } \\
\hline \multicolumn{5}{|l|}{ Frequency of pain in previous week } \\
\hline None of the time & 133 & $(31 \%)$ & 180 & $(27 \%)$ \\
\hline Once or twice & 143 & (33\%) & 161 & $(25 \%)$ \\
\hline A few times & 79 & $(18 \%)$ & 140 & $(21 \%)$ \\
\hline Fairly often & 29 & $(7 \%)$ & 64 & $(10 \%)$ \\
\hline Very often & 16 & $(4 \%)$ & 38 & $(6 \%)$ \\
\hline Every day & 29 & $(7 \%)$ & 74 & $(11 \%)$ \\
\hline
\end{tabular}


Table 1 Continued

\begin{tabular}{|c|c|c|c|c|}
\hline & \multicolumn{2}{|c|}{$\begin{array}{l}\text { Self-reported } \\
(\mathrm{n}=429)\end{array}$} & \multicolumn{2}{|c|}{$\begin{array}{l}\text { Parent-reported } \\
(\mathrm{n}=657)\end{array}$} \\
\hline & $\mathbf{n}$ & $(\%)$ & $\mathrm{n}$ & $(\%)$ \\
\hline \multicolumn{5}{|c|}{ Severity of pain in previous week } \\
\hline None & 130 & $(30 \%)$ & 180 & $(27 \%)$ \\
\hline Very mild & 94 & $(22 \%)$ & 100 & $(15 \%)$ \\
\hline Mild & 96 & $(22 \%)$ & 133 & $(20 \%)$ \\
\hline Moderate & 64 & $(15 \%)$ & 176 & $(27 \%)$ \\
\hline Severe & 26 & $(6 \%)$ & 55 & $(8 \%)$ \\
\hline Very severe & 19 & $(4 \%)$ & 13 & $(2 \%)$ \\
\hline \multicolumn{5}{|c|}{ Emotional difficulties score (by quartile) ${ }^{*}$} \\
\hline $0-1$ & 98 & $(23 \%)$ & 179 & $(27 \%)$ \\
\hline$>1-3$ & 146 & $(34 \%)$ & 206 & $(31 \%)$ \\
\hline$>3-5$ & 109 & $(25 \%)$ & 164 & $(25 \%)$ \\
\hline$>5-10$ & 72 & $(17 \%)$ & 106 & $(16 \%)$ \\
\hline Information not available & 4 & $(1 \%)$ & 2 & $(0 \%)$ \\
\hline \multicolumn{5}{|l|}{ Total stress score (by quartile) $\dagger$} \\
\hline $36-64$ & 127 & $(30 \%)$ & 163 & $(25 \%)$ \\
\hline 6580 & 118 & $(28 \%)$ & 162 & $(25 \%)$ \\
\hline $81-97$ & 92 & $(21 \%)$ & 167 & $(25 \%)$ \\
\hline $98-147$ & 81 & $(19 \%)$ & 152 & $(23 \%)$ \\
\hline Information not available & 11 & $(3 \%)$ & 13 & $(2 \%)$ \\
\hline
\end{tabular}

*Higher scores indicate more emotional difficulties.

tHigher scores indicate more stress.

further region (northwest Germany) ascertained 75 cases from multiple sources. The 818 children who entered SPARCLE1 were followed up when aged 13 to 17 years; 594 (73\%) agreed to participate. In order to maintain statistical power for crosssectional analyses, ${ }^{7} 9$ SPARCLE2 additionally sampled from young people eligible for SPARCLE1 who had not participated in it. Seventy-three agreed to participate and hence the final sample for SPARCLE2 comprised 667 young people, distributed by region as shown in table 1 .

\section{Procedure}

Researchers visited families in their homes, if possible when the young people were aged 13 to 17 years. Parents were asked to report on the measures below for all the young people. Young people who could self-report were asked to report their pain.

\section{Measures}

1. Any pain, measured using the Bodily Pain and Discomfort items of the Child Health Questionnaire. ${ }^{11}$ The items are valid and reliable ${ }^{12} 13$ and record frequency of pain (none of the time, once or twice, a few times, fairly often, very often, every day) and severity (none, very mild, mild, moderate, severe, very severe); we changed the timeframe to 1 week to accord with the wider SPARCLE study.

2. Site and circumstances of pain, as shown in the left hand column of table 2, recording frequency and severity in the previous week using the response categories above.

3. Severity of pain during treatment over the previous year (table 2) using the response categories above.

4. Emotional difficulties score (EDS) from the Strengths and Difficulties Questionnaire. ${ }^{14} 15$

5. Parenting stress using the total stress score from the Parenting Stress Index Short Form. ${ }^{16}$
6. Impairment: walking ability described by gross motor function ${ }^{17}$; fine motor function ${ }^{18}$; seizures; feeding; communication; intellectual ability ${ }^{19}$; and CP type.

7. Sociodemographic characteristics: parents' employment and educational qualifications, family structure, area of domicile, child's school type.

\section{Statistical methods}

To estimate the population prevalence of any pain, we dichotomised severity of pain as none/any (from very mild to very severe) and restricted the sample to the young people aged 13 to 17 in SPARCLE2 who had participated in SPARCLE1 and for whom sampling weights were therefore available; young people in northwest Germany were excluded as this region did not sample from population-based registers.

For all other statistical analysis, pain was not dichotomised; we used proportional odds ordinal regression which retained all six categories of severity and frequency of pain. ${ }^{20}$ We modelled the association between pain and covariates (impairments, sociodemographic characteristics, EDS, total stress score), stratifying by region. For analysis of trend, walking ability was treated as continuous; for all other analyses, covariates were treated as categorical. Four models, corresponding to young people's and parents' responses were developed. We first performed univariable analyses, relating pain to each covariate in turn. We then used forwards stepwise regression, followed by backwards steps, to select covariates to include in a multivariable model. We set the $p$ value for entry of covariates as $p<0.05$ and, to lessen the probability of chance findings due to multiple hypotheses testing, we set the $\mathrm{p}$ value for removal of covariates at 0.01 . We derived $\mathrm{p}$ values from the likelihood ratio test statistic. We checked for an interaction between significant covariates. We performed sensitivity analyses: (a) limiting the sample to young people who had responded to SPARCLE1 and for whom 
Table 2 Site and circumstances of pain severity in previous week, by walking ability*

\begin{tabular}{|c|c|c|c|c|c|c|c|c|c|c|c|c|c|c|c|c|}
\hline & \multicolumn{8}{|c|}{ (a) Self-report of pain by young people } & \multicolumn{8}{|c|}{ (b) Parent-report of their child's pain } \\
\hline & \multicolumn{8}{|c|}{ Walking ability (GMFCS) } & \multicolumn{8}{|c|}{ Walking ability (GMFCS) } \\
\hline & \multicolumn{2}{|l|}{ All } & \multirow{2}{*}{$\begin{array}{l}\text { I } \\
\%\end{array}$} & \multirow{2}{*}{$\begin{array}{l}\text { II } \\
\% \\
\end{array}$} & \multirow{2}{*}{$\begin{array}{l}\text { III } \\
\%\end{array}$} & \multirow{2}{*}{$\begin{array}{l}\text { IV } \\
\%\end{array}$} & \multirow{2}{*}{$\begin{array}{l}\mathbf{V} \\
\%\end{array}$} & \multirow{2}{*}{ p Value } & \multicolumn{2}{|l|}{ All } & \multirow{2}{*}{$\begin{array}{l}\text { I } \\
\%\end{array}$} & \multirow{2}{*}{$\begin{array}{l}\text { II } \\
\%\end{array}$} & \multirow{2}{*}{$\begin{array}{l}\text { III } \\
\%\end{array}$} & \multirow{2}{*}{$\begin{array}{l}\text { IV } \\
\%\end{array}$} & \multirow{2}{*}{$\begin{array}{l}\mathbf{V} \\
\%\end{array}$} & \multirow{2}{*}{ p Value } \\
\hline & $\mathrm{N}$ & $\%$ & & & & & & & $\mathrm{~N}$ & $\%$ & & & & & & \\
\hline \multicolumn{17}{|l|}{ Site of pain (in previous week) } \\
\hline Headaches & 423 & 34 & 39 & 38 & 36 & 18 & 19 & 0.004 & 629 & 30 & 33 & 40 & 24 & 31 & 20 & 0.002 \\
\hline Stomach & 422 & 26 & 26 & 30 & 25 & 24 & 27 & 0.49 & 634 & 32 & 24 & 33 & 23 & 42 & 44 & $<0.001$ \\
\hline Back & 420 & 27 & 27 & 24 & 28 & 22 & 41 & 0.12 & 632 & 25 & 19 & 20 & 23 & 31 & 38 & $<0.001$ \\
\hline Arms & 416 & 18 & 19 & 20 & 14 & 12 & 17 & 0.10 & 630 & 14 & 9 & 17 & 13 & 13 & 22 & 0.020 \\
\hline Hips & 421 & 14 & 13 & 12 & 14 & 18 & 22 & 0.07 & 635 & 21 & 9 & 16 & 17 & 28 & 44 & $<0.001$ \\
\hline Legs & 413 & 40 & 39 & 41 & 47 & 40 & 37 & 0.19 & 634 & 43 & 37 & 48 & 49 & 48 & 41 & 0.07 \\
\hline Operation sites & 411 & 10 & 5 & 12 & 14 & 16 & 17 & $<0.001$ & 624 & 14 & 5 & 16 & 21 & 19 & 21 & $<0.001$ \\
\hline \multicolumn{17}{|c|}{ Circumstances of pain (in previous week) } \\
\hline At rest from spasms & 413 & 13 & 10 & 13 & 16 & 20 & 14 & 0.04 & 632 & 17 & 8 & 16 & 16 & 18 & 35 & $<0.001$ \\
\hline At rest, from splints or restraints & 410 & 12 & 8 & 13 & 21 & 18 & 6 & 0.03 & 625 & 20 & 9 & 19 & 25 & 31 & 29 & $<0.001$ \\
\hline On swallowing or feeding & 410 & 3 & 2 & 3 & 4 & 4 & 6 & 0.12 & 627 & 6 & 4 & 3 & 1 & 11 & 11 & $<0.001$ \\
\hline On moving & 414 & 28 & 19 & 36 & 35 & 29 & 42 & $<0.001$ & 634 & 35 & 19 & 35 & 45 & 52 & 42 & $<0.001$ \\
\hline On changing or dressing & 413 & 5 & 2 & 3 & 4 & 8 & 19 & $<0.001$ & 627 & 15 & 4 & 6 & 12 & 26 & 38 & $<0.001$ \\
\hline In bed at night & 415 & 17 & 16 & 14 & 11 & 22 & 32 & 0.02 & 633 & 22 & 11 & 15 & 23 & 32 & 38 & $<0.001$ \\
\hline Short unexpected pains & 413 & 30 & 27 & 41 & 28 & 22 & 33 & 0.25 & 627 & 25 & 19 & 24 & 22 & 29 & 36 & $<0.001$ \\
\hline \multicolumn{17}{|l|}{ Pain during therapy (in previous year) } \\
\hline During physiotherapy & 339 & 45 & 38 & 42 & 50 & 62 & 50 & 0.002 & 505 & 50 & 40 & 51 & 46 & 58 & 60 & $<0.001$ \\
\hline During other therapy & 160 & 9 & 4 & 11 & 14 & 17 & 6 & 0.32 & 281 & 18 & 8 & 17 & 17 & 22 & 29 & 0.003 \\
\hline During botulinum injections & 142 & 26 & 22 & 28 & 35 & 21 & 36 & 0.42 & 233 & 29 & 16 & 33 & 44 & 34 & 29 & 0.32 \\
\hline
\end{tabular}

p, Significance of trend of pain over levels of walking ability, estimated using ordinal regression which retained all six categories of pain.

$\mathrm{N}$, Number included: data were unavailable if Gross Motor Function Classification System (GMFCS) or severity of pain were not reported or if the young person had not received the relevant therapy.

$\%$, Percentage with severity of pain from very mild to very severe.

* Presence of pain was defined by severity in any category from very mild to very severe.

sampling weights that reflected the sampling design were available; and (b) retaining the entire sample but additionally adjusting for factors associated with non-response. ${ }^{8} 921$

Stata V.12 was used for analysis.

\section{Ethics}

Ethics approval was obtained or a statement that only registration was required as appropriate in each country. Signed consent was obtained from all parents and from young people who could give meaningful consent.

\section{RESULTS}

Of the 667 young people in SPARCLE2, 429 (64\%) reported their own pain; parents' reports of their child's pain were available for 657 (99\%). The distributions of some impairments, some sociodemographic variables, pain, EDS and parenting stress score are presented in table 1 . The Spearman rank correlations between all pairs of types of impairment (except CP type) were strong $(\rho=0.24$ to 0.75$)$ and statistically significant $(\mathrm{p}<0.0001)$. About one third of the young people reported no pain in the previous week, a third reported pain once or twice, and a third reported more frequent pain.

\section{Prevalence of pain}

Based on severity, the proportion of young people with any pain in the previous week was $70 \%$ by self-report and $73 \%$ by parent-report. Using the prevalence sample, these proportions corresponded to population prevalences of self-reported pain of $74 \%$ (95\% CI $69 \%$ to $79 \%$ ) and of parent-reported pain of
$77 \%$ (95\% CI $73 \%$ to $81 \%$ ). Results based on frequency of pain were similar.

\section{Sites and circumstances of pain}

The percentages of young people reporting any pain in the previous week at specific sites and in specific circumstances are presented in table 2 . The most common sites for pain were legs $(40 \%)$ and head (34\%). Over a quarter reported stomach or back pain, pain on moving or short unexpected pains. Those with more severe impairment of walking ability were significantly more likely to report pain on moving, changing or dressing, or at operation sites. Those with less severe impairment of walking ability tended to report more headaches.

The distribution of parent-reported pain was similar, although trends over walking ability were more marked. Parents perceived their child as experiencing more pain in the stomach, back and hips, and at operation sites, and more pain in all the circumstances considered if they had more impaired walking ability. Results based on frequency of pain were similar.

\section{Pain during therapy}

Almost half of young people who could self-report and who had received physiotherapy in the previous year reported pain during therapy; $30 \%$ reported very mild or mild pain, $9 \%$ moderate pain and 6\% severe or very severe pain. Pain during physiotherapy was significantly more likely to occur if the young person had more severely impaired walking ability (table 2). Over a quarter of young people reported pain during botulinum injections; $11 \%$ reported very mild or mild pain, $4 \%$ 
Table 3 ORs from multivariable ordinal regression models of young people's pain in previous week*

\begin{tabular}{|c|c|c|c|c|c|c|}
\hline & \multicolumn{3}{|c|}{ Severity of pain } & \multicolumn{3}{|c|}{ Frequency of pain } \\
\hline & ORt & $(95 \% \mathrm{Cl})$ & p Value & ORt & $(95 \% \mathrm{Cl})$ & $\mathrm{p}$ Value \\
\hline \multicolumn{7}{|l|}{ Self-report of pain by young person $(n=425)$} \\
\hline Gender & & & $<0.0001$ & & & 0.0006 \\
\hline Boy & 1.0 & & & 1.0 & & \\
\hline Girl & 2.1 & (1.5 to 3.0$)$ & & 1.9 & (1.3 to 2.7 ) & \\
\hline Emotional difficulties score (by quartile) & & & 0.001 & & & 0.0002 \\
\hline $0-1$ & 1.0 & & & 1.0 & & \\
\hline$>1-3$ & 1.4 & (0.9 to 2.3 ) & & 1.3 & (0.8 to 2.2 ) & \\
\hline$>3-5$ & 1.8 & (1.1 to 3.0$)$ & & 1.8 & (1.1 to 3.1$)$ & \\
\hline$>5-10$ & 3.1 & (1.7 to 5.6$)$ & & 3.5 & (1.9 to 6.3 ) & \\
\hline \multicolumn{7}{|l|}{ Parent-report of their child's pain $(n=655)$} \\
\hline Emotional difficulties score (by quartile) & & & $<0.0001$ & & & $<0.0001$ \\
\hline $0-1$ & 1.0 & & & 1.0 & & \\
\hline$>1-3$ & 1.7 & (1.2 to 2.4$)$ & & 1.5 & (1.1 to 2.2 ) & \\
\hline$>3-5$ & 2.4 & (1.6 to 3.5$)$ & & 2.0 & (1.4 to 3.0$)$ & \\
\hline$>5-10$ & 4.2 & (2.7 to 6.6$)$ & & 4.1 & (2.6 to 6.4 ) & \\
\hline Walking ability (captured by gross motor function) & & & $<0.0001$ & & & $<0.0001$ \\
\hline I. Walks without limitation & 1.0 & & & 1.0 & & \\
\hline II. Walks with limitation & 1.4 & (1.0 to 2.2$)$ & & 1.3 & (0.9 to 2.0$)$ & \\
\hline III. Walks with assistive devices & 1.5 & (0.9 to 2.4 ) & & 1.6 & (1.0 to 2.5$)$ & \\
\hline IV. Unable to walk, limited self-mobility & 2.1 & (1.3 to 3.2$)$ & & 2.0 & (1.3 to 3.0$)$ & \\
\hline V. Unable to walk, severely limited self-mobility & 5.1 & (3.4 to 7.6$)$ & & 4.9 & (3.3 to 7.4 ) & \\
\hline
\end{tabular}

*All models were stratified by region. Young people with missing data, either on pain outcomes or on factors included in the model, were excluded.

tORs $<1.0$ indicate a higher level of pain in that group than in the reference group.

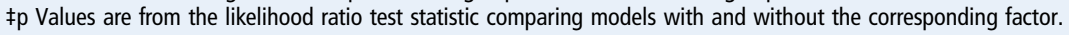

moderate pain and $11 \%$ severe or very severe pain. Parents' reports confirmed these findings.

\section{Associations of pain}

In univariable analysis of any self-reported pain (as captured by the instrument described in Measures (1) in the Methods section), the severity did not vary significantly $(p<0.01)$ with any type of impairment or with any sociodemographic characteristic except young people's gender: girls tended to report more severe pain. Young people with a higher EDS also tended to report more severe pain. Both gender and EDS remained statistically significant in a multivariable model (table 3). Results for frequency of pain were similar. Sensitivity analyses yielded similar results.

In univariable analysis of parents' reports of their child's pain, pain was significantly more frequent and more severe if the parents were more stressed or if their child was more severely impaired, or was a girl, or had a higher EDS. However, these factors were correlated. Thus, in multivariable models only walking ability and EDS remained significantly associated with pain. We found no evidence of interaction between walking ability and EDS. Sensitivity analyses yielded similar results.

In order to understand better these differences between selfreported and parent-reported pain, we restricted analysis of parent-reported pain to young people who could self-report. Results in this sub-sample were similar to those in the complete sample: in particular, the relationship between parent-reported pain and walking ability remained significant.

\section{Comparison of parents' reports of their child's pain and young people's reports of pain}

The relationship between parent- and young person-reports of pain, (as captured by the instrument described in Measures
(1) in the Methods section), is shown in table 4. If parent- and self-report had agreed completely, the percentages in bold would be $100 \%$. Although parent- and self-reported pain were significantly correlated (Spearman rank correlation $=0.45$, $\mathrm{p}<0.0001$ ), parents tended to overestimate their child's pain if self-reported pain was infrequent or mild and underestimate it if the self-reported pain was frequent or severe.

\section{DISCUSSION}

\section{Main findings}

About three quarters of young people aged 13 to 17 years with CP had pain in the previous week according to both self- and parent-reports. Forty per cent experienced pain in the legs and over one quarter experienced pain in the head, stomach or back, pain on moving or short unexpected pains. Almost half of the young people who had received physiotherapy had experienced pain during therapy; about a quarter of those who received botulinum injections experienced pain. Girls generally reported more pain than boys. More pain was associated with more emotional difficulties according to both the self- and parent-reports. Parents tended to report that their child had more pain if the child was more severely impaired; this trend was much less evident for self-reported pain.

\section{Strengths and weaknesses}

Participants were representative of all young people with CP across the range of severity of impairment, as they were sampled from nine geographic areas, eight of which had population based registers. Analyses of trends and associations did not dichotomise pain; they used ordinal regression based on information in all six categories of pain. Estimation of prevalence required dichotomisation and we chose the cut-point as no pain/any pain in order to allow comparison with other papers 
Table 4 Relationship between self-reported and parent-reported pain in previous week $(n=421)$

\begin{tabular}{|c|c|c|c|c|c|c|c|c|c|c|c|c|c|c|}
\hline \multirow[b]{2}{*}{ Self-report of pain by young person } & \multicolumn{14}{|c|}{ Parent-report of their child's pain } \\
\hline & \multicolumn{2}{|c|}{$\begin{array}{l}\text { None of the } \\
\text { time }\end{array}$} & \multicolumn{2}{|c|}{$\begin{array}{l}\text { Once or } \\
\text { twice }\end{array}$} & \multicolumn{2}{|c|}{ A few times } & \multicolumn{2}{|c|}{ Fairly often } & \multicolumn{2}{|c|}{ Very often } & \multicolumn{2}{|c|}{ Every day } & \multicolumn{2}{|l|}{ Total } \\
\hline \multicolumn{15}{|l|}{ Frequency of pain } \\
\hline None of the time & 66 & $(50 \%)$ & 33 & $(25 \%)$ & 20 & $(15 \%)$ & 4 & $(3 \%)$ & 3 & $(2 \%)$ & 5 & $(4 \%)$ & 131 & $(100 \%)$ \\
\hline Once or twice & 36 & $(26 \%)$ & 49 & $(35 \%)$ & 33 & $(24 \%)$ & 9 & $(6 \%)$ & 5 & $(4 \%)$ & 8 & $(6 \%)$ & 140 & $(100 \%)$ \\
\hline A few times & 10 & $(13 \%)$ & 24 & $(31 \%)$ & 25 & $(32 \%)$ & 5 & $(6 \%)$ & 7 & $(9 \%)$ & 7 & $(9 \%)$ & 78 & $(100 \%)$ \\
\hline Fairly often & 3 & $(11 \%)$ & 7 & $(26 \%)$ & 6 & $(22 \%)$ & 5 & (19\%) & 2 & $(7 \%)$ & 4 & $(15 \%)$ & 27 & $(100 \%)$ \\
\hline Very often & 2 & $(13 \%)$ & 0 & $(0 \%)$ & 4 & $(25 \%)$ & 5 & $(31 \%)$ & 3 & $(19 \%)$ & 2 & $(13 \%)$ & 16 & $(100 \%)$ \\
\hline \multirow[t]{2}{*}{ Every day } & 0 & $(0 \%)$ & 2 & $(7 \%)$ & 7 & $(24 \%)$ & 4 & $(14 \%)$ & 5 & $(17 \%)$ & 11 & $(38 \%)$ & 29 & $(100 \%)$ \\
\hline & \multicolumn{2}{|c|}{ None } & \multicolumn{2}{|c|}{ Very mild } & \multicolumn{2}{|c|}{ Mild } & \multicolumn{2}{|c|}{ Moderate } & \multicolumn{2}{|c|}{ Severe } & \multicolumn{2}{|c|}{ Very severe } & \multicolumn{2}{|l|}{ Total } \\
\hline \multicolumn{15}{|l|}{ Severity of pain } \\
\hline None & 66 & $(52 \%)$ & 31 & $(24 \%)$ & 15 & $(12 \%)$ & 13 & $(10 \%)$ & 3 & $(2 \%)$ & 0 & $(0 \%)$ & 128 & $(100 \%)$ \\
\hline Very mild & 24 & $(26 \%)$ & 23 & $(24 \%)$ & 28 & $(30 \%)$ & 17 & $(18 \%)$ & 2 & $(2 \%)$ & 0 & $(0 \%)$ & 94 & $(100 \%)$ \\
\hline Mild & 14 & $(15 \%)$ & 18 & $(19 \%)$ & 28 & $(30 \%)$ & 24 & $(26 \%)$ & 9 & $(10 \%)$ & 1 & $(1 \%)$ & 94 & $(100 \%)$ \\
\hline Moderate & 9 & $(15 \%)$ & 8 & $(13 \%)$ & 13 & $(21 \%)$ & 23 & $(37 \%)$ & 8 & $(13 \%)$ & 1 & $(2 \%)$ & 62 & $(100 \%)$ \\
\hline Severe & 3 & $(12 \%)$ & 2 & $(8 \%)$ & 4 & $(15 \%)$ & 9 & $(35 \%)$ & 7 & $(27 \%)$ & 1 & $(4 \%)$ & 26 & $(100 \%)$ \\
\hline Very severe & 1 & $(6 \%)$ & 2 & $(12 \%)$ & 4 & $(24 \%)$ & 4 & $(24 \%)$ & 2 & $(12 \%)$ & 4 & $(24 \%)$ & 17 & $(100 \%)$ \\
\hline
\end{tabular}

on $\mathrm{CP}^{1} 222$ and papers on pain in the general population. ${ }^{23} 24$ Although non-response by families was $37 \%$ in SPARCLE1, and $27 \%$ of those in SPARCLE1 dropped out in SPARCLE2, sensitivity analyses adjusting for factors associated with non-response yielded similar results. ${ }^{8} \quad 21$ The weights, which reflected the sampling design, allowed extrapolation from the reports of pain in our sample to an estimate of the population prevalence of pain in young people with CP.

\section{Comparison with other studies}

A study of parent-reported pain in the previous week in the general population of 7 to 17 -year-olds found $15 \%$ had headaches, $8 \%$ abdominal pain and $5 \%$ back pain, ${ }^{23}$ much lower than our rates. A study of 10 to 18 -year-olds found the prevalence of self-reported pain in the previous week to be $34 \%,{ }^{24}$ lower than the $74 \%$ we report. Thus, young people with CP generally experience more pain than those without, and this has clear clinical implications.

Studies in young people of a similar age with CP report lower prevalence of pain than we do-for example, 56\% in 11 to 18 -year-olds ${ }^{1}$ and $62 \%$ in 8 to 18 -year-olds ${ }^{2}$ - even though they asked about pain over the previous month rather than the previous week. However, our study was larger, more representative, distinguished self- and parent-reported pain and asked about pain related to healthcare procedures. One study ${ }^{1}$ found, as we did, that a higher proportion of girls reported pain $(64 \%$ and $50 \%$, respectively). A similar gender difference is also found in the general population, ${ }^{22}$ and may be due to neurophysiological differences. ${ }^{25}$ The association of pain with emotional difficulties in 13 to 17 -year-olds is consistent with findings in young people without disability; for example, young people with severe chronic pain reported high levels of anxiety and depression. ${ }^{26}$ If the association is causal, then the direction is unclear and may indeed be in both directions.

Between childhood and adolescence, the prevalence of selfreported pain increased from $60 \%(95 \% \text { CI } 54 \% \text { to } 65 \%)^{4}$ to $74 \%$ (95\% CI 69\% to $79 \%$ ).

\section{Implications}

The prevalence of pain in young people with CP is high. This is important, not only because of the unpleasantness of pain but also because of the strong association of pain in CP with lower subjective well-being and reduced participation. ${ }^{5} 6$ Given that pain is so prevalent among young people with CP, strategies to reduce it must be either absent or inadequate.

CP is often accompanied by painful secondary musculoskeletal problems such as hip subluxation or dislocation, spinal scoliosis and muscle contractures in the upper and lower limbs. Furthermore, common clinical interventions, such as gastrostomy tubes, botulinum injections, assistive devices and physiotherapy, may cause pain; we found that almost half of those receiving some form of therapy reported experiencing pain during therapy. It is difficult to justify therapy that causes pain unless good evidence indicates that it improves some aspect of a young person's life-so clinicians should carefully consider the efficacy of therapies that have the potential to cause pain. A study of children with $\mathrm{CP}^{27}$ found that assisted stretching was the daily activity most frequently identified as painful. This is especially worrying in the light of recent reviews of the effectiveness of passive stretching in people with $\mathrm{CP}^{28-30}$ which conclude that stretching does not produce clinically important change in contractures, function or disability. A further review found little evidence for any benefit of postural management but evidence of disadvantages, including pain. ${ }^{31}$ We recommend that adverse effects and benefits of treatment are recorded and assessed to inform effective use of such treatments.

At consultations, clinicians should ask parents and young people directly about their pain, and should develop pain management plans incorporating preventive and responsive elements. For instance botulinum toxin may help hip pain, ${ }^{32}$ intrathecal baclofen may help painful spasms, ${ }^{33}$ pain during physiotherapy can be minimised ${ }^{34} 35$ and cognitive behavioural therapy may help coping with pain. Emotional health and pain are associated, so clinicians should assess if emotional factors could be exacerbating pain.

As most people with CP live well into adulthood, our findings are also important for adult care. 


\section{Future research}

Future research should focus on identifying the type of pain experienced and the elements of therapy that appear to cause it. In particular, these studies should assess how much stretching and mobilisation is required to maintain function or range of motion and whether can this be achieved without significant pain. In order to do this, more studies will need to be undertaken in the clinical setting.

Acknowledgements We are grateful to the families who participated in SPARCLE2 and to the study's research associates-Alberto Furlan, Audrey Guyard, Louisa Henriksen, Caroline Joyce, Heidi Kiecksee, Karin Lindh, Nichola McCullough, Laura O'Connell, Marion Rapp, Mariane Sentenac — for their enthusiasm and dedication to contacting families and collecting high quality data.

Collaborators The SPARCLE group is: AC, KNP and HOD, Newcastle University, Newcastle, UK; Eva Beckung, Malin Nystrand, Göteborg University, Göteborg, Sweden; Jackie Parkes, Queens University, Belfast, UK; Jérôme Fauconnier, Université Joseph Fournier, Grenoble, France; Alan Lyons, Enable Ireland, Cork, Ireland; Susan Michelsen, NIPH, Copenhagen, Denmark; Marco Marcelli, ASLV, Viterbo, Italy; Catherine Arnaud, INSERM, Toulouse, France; Ute Thyen and Marion Rapp, Lübeck, Germany.

Contributors $A C$ is the corresponding author and guarantor of the article; participated in the planning of the study, coordinated the study and took overall responsibility for the delivery of the work; participated in writing the paper and approved the final version; had full access to all the data in the study and had final responsibility for the decision to submit for publication. KNP was responsible for the day to day administration of the study and data collection in one centre, participated in maintaining the quality of the data, attended workshops, and drafted the paper. HOD performed all statistical analysis, participated in maintaining the quality of the data and in writing the paper; saw and approved the final version. CA participated in the planning of this study, was responsible for data collection in one centre, attended workshops and planning analysis and saw and approved the final version. AL participated in the planning of this study, was responsible for data collection in one centre, attended workshops and planning analysis and saw and approved the final version.

Funding Wellcome Trust WT 086315 A1A (UK and Ireland); Medical Faculty of University of Lübeck E40-2009 and E26-2010 (Germany); CNSA, INSERM, MiReDREES, IRESP (France); Ludvig and Sara Elsass Foundation (Denmark); The Spastics Society-Vanforefonden (Denmark); Cooperativa Sociale 'Gli Anni in Tasca', Viterbo (Italy); Fondazione Carivit, Viterbo (Italy); Goteborg University-Riksforbundet for Rorelsehindrade Barn och Ungdomar; Folke Bernadotte Foundation (Sweden).

Competing interests None.

Ethics approval Newcastle and North Tyneside NHS Research Ethics Committee.

Provenance and peer review Not commissioned; externally peer reviewed.

Data sharing statement The data from this paper and the associated dataset can be examined in more detail on request from the corresponding author, Allan Colver. The data from the wider SPARCLE study will be available for secondary analyses once the the SPARCLE collaborators have completed their planned analyses; this will be in about 18 months.

Open Access This is an Open Access article distributed in accordance with the Creative Commons Attribution Non Commercial (CC BY-NC 3.0) license, which permits others to distribute, remix, adapt, build upon this work non-commercially, and license their derivative works on different terms, provided the original work is properly cited and the use is non-commercial. See: http://creativecommons.org/ licenses/by-nc/3.0/

\section{REFERENCES}

1 Doralp S, Bartlett $D$. The prevalence, distribution, and effect of pain among adolescents with cerebral palsy. Pediatr Phys Ther 2010;22:26-33.

2 Ramstad K, Jahnsen R, Skjeldal OH, et al. Characteristics of recurrent musculoskeletal pain in children with cerebral palsy aged 8 to 18 years. Dev Med Child Neurol 2011:1013-18.

3 Colver A. Study protocol: SPARCLE - a multi-centre European study of the relationship of environment to participation and quality of life of children with cerebral palsy. BMC Public Health 2006:6:105.

4 Parkinson KN, Gibson L, Dickinson HO, et al. Pain in children with cerebral palsy: a cross-sectional multicentre European study. Acta Paediatr 2010;99:446-51.

5 Dickinson HO, Parkinson KN, Ravens-Sieberer U, et al. Self-reported quality of life of 8-12-year-old children with cerebral palsy: a cross-sectional European study. Lancet 2007:369:2171-8
6 Fauconnier J, Dickinson HO, Beckung $\mathrm{E}$, et al. Participation in life situations of 8-12 year old children with cerebral palsy: cross sectional European study. BMJ 2009;338:b1458.

7 Colver AF, Dickinson HO. Study protocol: determinants of participation and quality of life of adolescents with cerebral palsy: a longitudinal study (SPARCLE2). BMC Public Health 2010;10:280

8 Dickinson $\mathrm{H}$, Parkinson $\mathrm{K}$, McManus V, et al. Assessment of data quality in a multi-centre cross-sectional study of participation and quality of life of children with cerebral palsy. BMC Public Health 2006;6:273.

9 Dickinson HO, Rapp M, Arnaud C, et al. Predictors of drop-out in a multi-centre longitudinal study of participation and quality of life of children with cerebral palsy. BMC Research Notes 2012;5:300.

10 SCPE. Prevalence and characteristics of children with cerebral palsy in Europe. Dev Med Child Neurol 2002:44:633-40.

11 Landgraf J, Abetz L, Ware JE. The CHQ: a user's manual (second printing). Boston, MA: HealthAct, 1999.

12 Norrby U, Nordholm L, Fasth A. Reliability and validity of the Swedish version of child health questionnaire. Scand I Rheumatol 2003:32:101-7.

13 Raat $\mathrm{H}$, Botterweck AM, Landgraf JM, et al. Reliability and validity of the short form of the child health questionnaire for parents (CHQ-PF28) in large random school based and general population samples. J Epidemiol Community Health 2005;59:75-82

14 Goodman R. Psychometric properties of the Strengths and Difficulties Questionnaire. J Am Acad Child Adolesc Psychiatry 2001;40:1337-45.

15 Muris $P$, Meesters $C$, van den Berg F. The Strengths and Difficulties Questionnaire (SDQ) — further evidence for its reliability and validity in a community sample of Dutch children and adolescents. Eur Child Adolesc Psychiatry 2003;12:1-8.

16 Abidin R. Parenting stress index professional manual. 3rd ed. Odessa, Florida, USA: Psychological Assessment Resources Inc. 1995.

17 Palisano R, Rosenbaum P, Walter $\mathrm{S}$, et al. Development and reliability of a system to classify gross motor function in children with cerebral palsy. Dev Med Child Neurol 1997:39:214-23.

18 Beckung $E$, Hagberg G. Neuroimpairments, activity limitations, and participation restrictions in children with cerebral palsy. Dev Med Child Neurol 2002;44:309-16.

19 White-Koning M, Arnaud C, Bourdet-Loubere S, et al. Subjective quality of life in children with intellectual impairment-how can it be assessed? Dev Med Child Neurol 2005;47:281-5.

20 Skrondal A, Rabe-Hesketh S. Generalized latent variable modelling: multilevel, longitudinal, and structural equation models. London: Chapman \& Hall, 2004.

21 Korn EL, Graubard BI. Analysis of large health surveys: accounting for the sampling design. J R Stat Soc Ser A Stat Soc 1995;158:263-95.

22 Sundblad GM, Saartok T, Engstrom LM. Prevalence and co-occurrence of self-rated pain and perceived health in school-children: age and gender differences. Eur J Pain 2007:11:171-80

23 Groholt E, Stigum H, Nordhagen R, et al. Recurrent pain in children, socio-economic factors and accumulation in families. Eur J Epidemiol 2003;18:965-75.

24 Roth-Isigkeit A, Thyen U, Raspe HH, et al. Reports of pain among German children and adolescents: an epidemiological study. Acta Paediatr 2004;93:258-63.

25 Wilson JF. The pain divide between men and women. Ann Intern Med 2006;144:461-4

26 Eccleston C, Crombez G, Scotford A, et al. Adolescent chronic pain: patterns and predictors of emotional distress in adolescents with chronic pain and their parents Pain 2004;108:221-9.

27 Hadden KL, von Baeyer CL. Pain in children with cerebral palsy: common triggers and expressive behaviors. Pain 2002;99:281-8.

28 Katalinic 0, Harvey L, Herbert R, et al. Stretch for the treatment and prevention of contractures. Cochrane Database Syst Rev 2010;9:CD007455.

29 Pin T, Dyke $P$, Chan M. The effectiveness of passive stretching in children with cerebral palsy. Dev Med Child Neurol 2006;48:855-62.

30 Franki I, Desloovere K, De Cat J, et al. The evidence-base for basic physical therapy techniques targeting lower limb function in children with cerebral palsy: a systematic review using the International Classification of Functioning, Disability and Health as a conceptual framework. J Rehabil Med 2012;44:385-95.

31 Gough M. Continuous postural management and the prevention of deformity in children with cerebral palsy: an appraisal. Dev Med Child Neurol 2009:51:105-10.

32 Lundy $\mathrm{CT}$, Doherty GM, Fairhurst CB. Botulinum toxin type A injections can be an effective treatment for pain in children with hip spasms and cerebral palsy. Dev Med Child Neurol 2009:51:705-10.

33 Ramstad K, Jahnsen R, Lofterod B, et al. Continuous intrathecal baclofen therapy in children with cerebral palsy - when does improvement emerge? Acta Paediatr 2010;99:1661-5.

34 von Baeyer $\mathrm{CL}$, Tupper SM. Procedural pain management for children receiving physiotherapy. Physiother Can 2010;62:327-37.

35 Swiggum $\mathrm{M}$, Hamilton $\mathrm{ML}$, Gleeson $\mathrm{P}$, et al. Pain in children with cerebral palsy: implications for pediatric physical therapy. Pediatr Phys Ther 2010;22:86-92. 